Original Research Paper

\title{
Experimental Validation of a Mathematical Model of the Operation of a Hydraulic Ram Pump with a Springs System
}

\author{
Andriamahefasoa Rajaonison and Hery Tiana Rakotondramiarana \\ Institute for the Management of Energy (IME), University of Antananarivo, Antananarivo, Madagascar
}

Article history

Received: 04-03-2020

Revised: 12-05-2020

Accepted: 12-06-2020

Corresponding Author:

Andriamahefasoa Rajaonison

Institute for the Management of

Energy (IME), University of

Antananarivo, Antananarivo,

Madagascar

Email: rajmahefasoa@gmail.com

\begin{abstract}
Water pumps, which usually require fuels or power, are for carrying water from water sources to a facility, generally a household or a farm in the countryside. The present study consists of conducting an experimental validation of a mathematical model that was developed in a previous work for simulating the functioning of a new form of the hydraulic ram pump, also known as the hydram pump. This new configuration differs from the conventional ones in that a springs system is incorporated. As this type of pump uses only water energy to operate, thanks to an overpressure called the «water hammer» phenomenon, the experiment could be carried out on a small scale in Antananarivo, Madagascar. Hence, this paper opens new research perspectives on the hydram pump. The recalibration of the model according to its experimental validation allows the dimensioning of any system, in any field, using this type of water pump.
\end{abstract}

Keywords: Hydram Pump, RASETA Pump, Waste Valve Stroke, Water Hammer, Recalibration

\section{Introduction}

The hydraulic ram pump can carry up water over a certain height between the watercourse and end-users (Sengupta and Narula, 2013). But unlike other water pumps, the hydram pump uses only water energy to operate. This is possible due to an overpressure called « water hammer » phenomenon. It results from the sudden stop of moving water having taken a certain velocity through a supply pipe. Although it could be harmful to pipelines, the overpressure pushes up water through a delivery pipe. Joseph Michel Montgolfier invented the hydram pump for the first time by the end of the 18th century (Maratos, 2003). Numerous studies were carried out to understand and simulate the functioning of a hydram pump (Sheikh et al., 2013; Inthachot et al., 2015; Deo et al., 2016; Hussin et al., 2017). Nevertheless, the pump studied in the present work is different from the others as a springs system equips both the waste valve and the delivery valve. Moreover, 4 springs connected to a valve replace the air chamber generally seen in conventional hydram pumps. At our state of knowledge, a scientific experimental study of this pump named the RASETA pump (Rasetarivelo, 2004) has never been done anteriorly.

This paper presents the experimental validation of a mathematical model that was developed in a previous study (Rajaonison and Rakotondramiarana, 2019) for simulating the operation of a hydram pump equipped with a springs system. More precisely, the model underwent a global sensitivity analysis based on a derived method Fourier Amplitude Sensitivity Test (FAST) for ranking in downward order the main effects and the second interaction effects of the various model parameters (Rakotondramiarana and Andriamamonjy, 2013). As a result, the most sensitive parameter of the studied model is the pump waste valve stroke (Rajaonison and Rakotondramiarana, 2019). Consequently, this paper focuses on the change of the pumped water flow while experimentally varying the pump waste valve stroke and keeping constant the other parameters involved in the operation of the pump as listed in (Rajaonison and Rakotondramiarana, 2019). Finally, the model is recalibrated according to the experimental data.

\section{Materials and Methods}

\section{Materials}

The experimental pump (Fig. 1) is made of plumbing components that can be locally found in specialized stores in Antananarivo, Madagascar. The dimension of each plumbing component is $3 / 4 "$.

Those components are one stop-valve, one modified brass foot-valve with a stainless steel filter as the waste valve, one brass spring-loaded check valve as the delivery valve, two brass T-screw connections, one brass 
elbow screw connection, one steel balloon with only one spring instead of four, eight brass pipe fitting nipples to connect the different components and one brass reduction connection at the pump outlet.

A thread seal tape is used to avoid water leakage due to connections.

The operation of the studied pump follows a cycle of 6 periods (Lansford and Dugan, 1941): The first period is the beginning until the complete closing of the waste valve by moving up. In the second period, the waste valve is fully closed and the delivery valve opens. After that, the delivery valve stays open in the third period. Follows the fourth period during which the delivery valve closes and the waste valve begins to open by moving down. Afterward, the fifth period is the time between the opening of the waste valve and the water loss start. Finally, during the sixth period, water losses initiate and the waste valve begins to close. As soon as this last period ends, the cycle starts again.

The studied pump (Fig. 1) is placed in an experimental pumping system as shown in Fig. 2. During the process of this pumping system, the experimental pump is fed through a supply pipe in polypropylene by a water source, which is a 20-liter-reservoir lifted to a height called supply height (Fig. 2). After the pump operation, as previously described, the pumped water is carried up to a height named delivery height through a delivery pipe in polypropylene, too (Fig. 2).

\section{Experimental Setup}

All data were processed with Matlab software (Matlab R2010a, 2010).
Before the experiment, the friction constant of the delivery valve was computed according to Lansford and Dugan (1941).

Precisely, the values of the delivery valve head loss were plotted (y-axis) versus water velocity ( $\mathrm{x}$-axis) to multiply by two times the gravity acceleration, the slope of the straight line that best fits the curve.

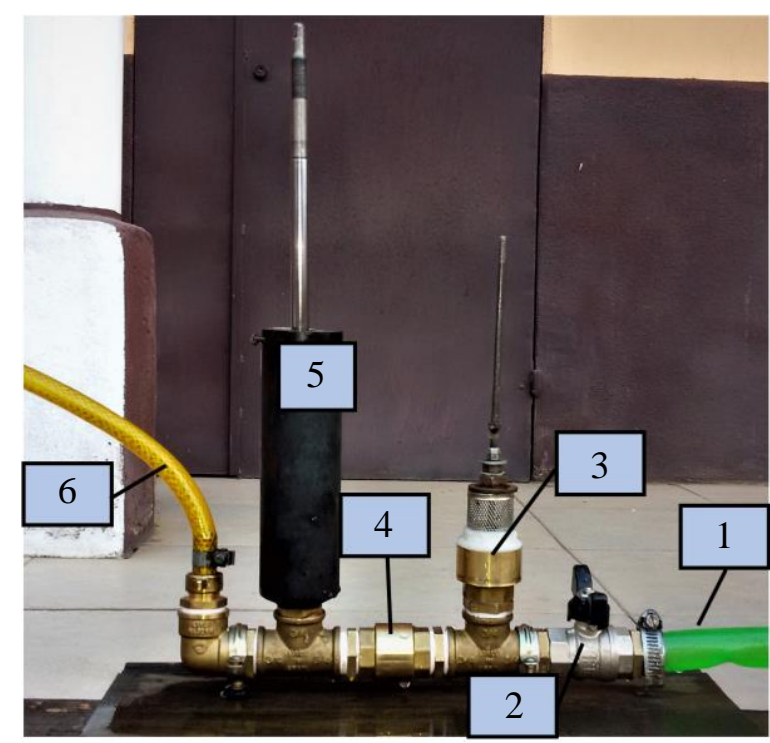

Fig. 1: Experimental pump; 1: supply pipe; 2: stop valve; 3: waste valve; 4: delivery valve; 5 : balloon with spring; 6: delivery pipe

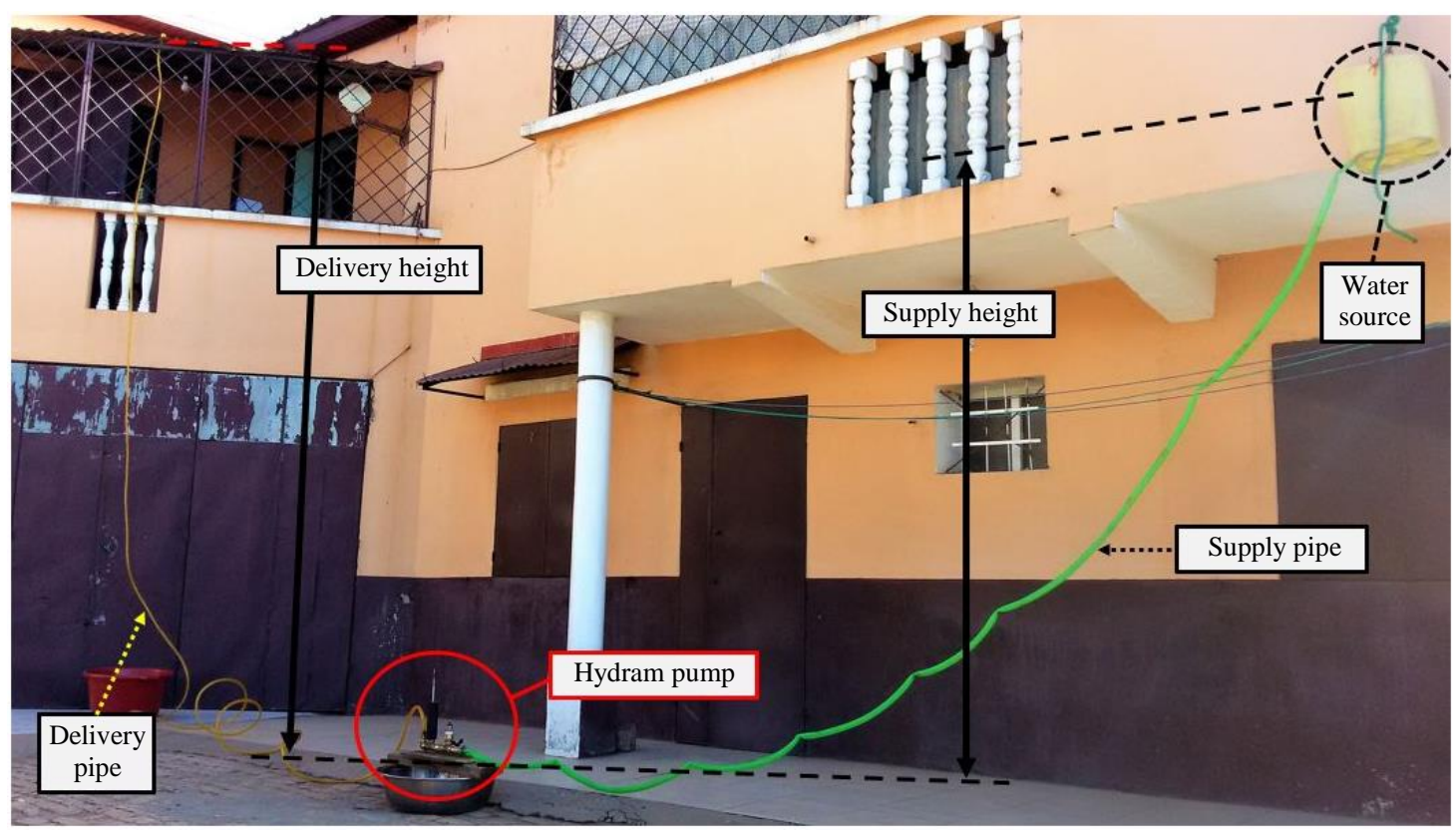

Fig. 2: Experimental pumping system 


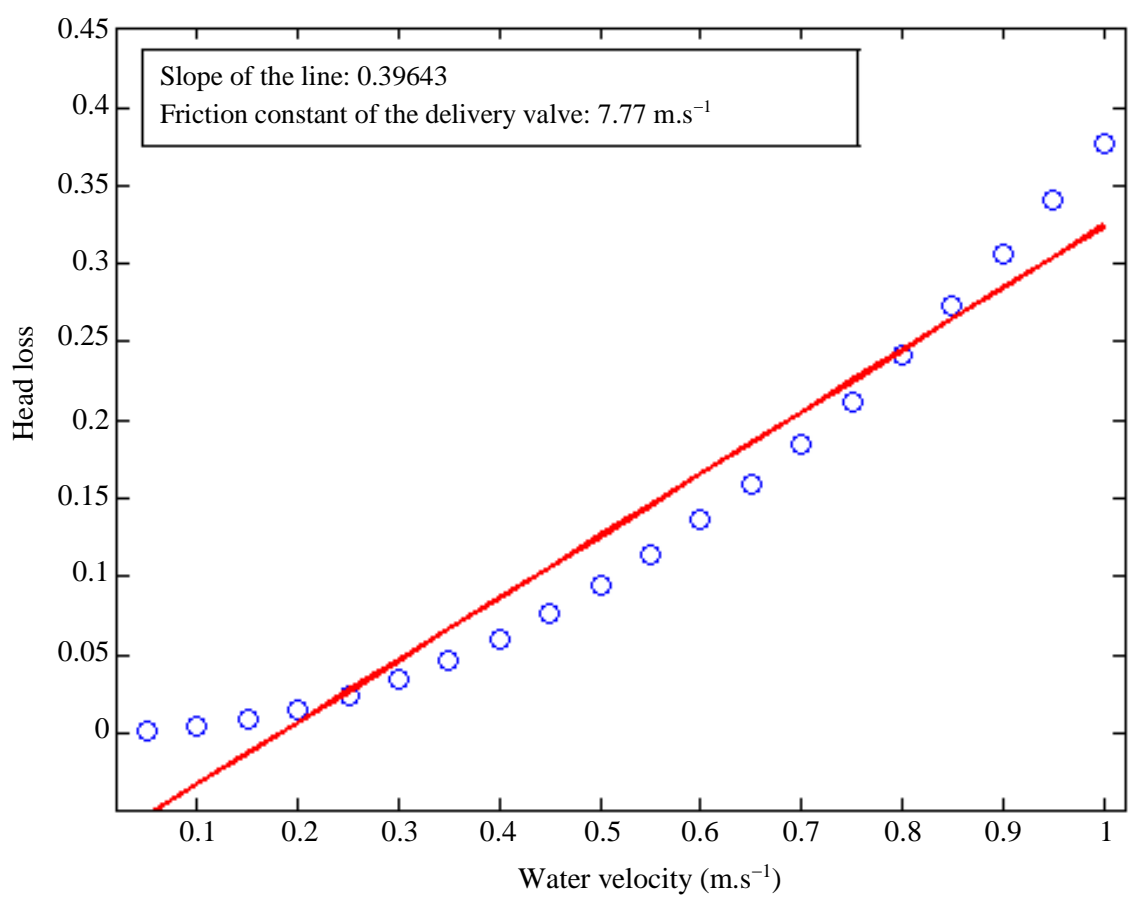

Fig. 3: Head loss at the delivery valve according to the water velocity

Table 1: Parameters of the experimental pump

\begin{tabular}{|c|c|c|}
\hline Parameters & Value & Unit \\
\hline Thickness of the disk of the waste valve & 0.001 & $\mathrm{~m}$ \\
\hline Modulus of elasticity or Young's modulus of the supply pipe & $5 \mathrm{E}+08$ & N.m ${ }^{-2}$ \\
\hline Delivery height & 4.89 & $\mathrm{~m}$ \\
\hline Supply height & 2.36 & $\mathrm{~m}$ \\
\hline Spring stiffness constant of the waste valve & 192.4 & N.m $m^{-1}$ \\
\hline Spring stiffness constant of the delivery valve & 387.1 & N.m $m^{-1}$ \\
\hline Stiffness of each spring in the spring balloon & 434.14 & N.m ${ }^{-1}$ \\
\hline Modulus of elasticity of water & $2.15 \mathrm{E}+09$ & N.m ${ }^{-2}$ \\
\hline Head loss coefficient of the delivery valve & 7.4 & - \\
\hline Length of the supply pipe from the supply tank to the center of the waste valve & 5.11 & $\mathrm{~m}$ \\
\hline Length of the supply pipe from the source to the center of the delivery valve & 5.17 & $\mathrm{~m}$ \\
\hline Length of the delivery pipe & 6.72 & $\mathrm{~m}$ \\
\hline Friction constant of the delivery valve & 7.77 & $\mathrm{~m} . \mathrm{s}^{-1}$ \\
\hline Weight of the moving part of the waste valve & 0.0388 & $\mathrm{~kg}$ \\
\hline Weight of the disc in the balloon & 0.280 & $\mathrm{~kg}$ \\
\hline Radius of the supply pipe & 0.011 & $\mathrm{~m}$ \\
\hline Radius of the delivery pipe & 0.0065 & $\mathrm{~m}$ \\
\hline Radius of the shrunk pipe & 0.01 & $\mathrm{~m}$ \\
\hline Radius of the disc in the balloon & 0.024 & $\mathrm{~m}$ \\
\hline Radius of the disc of the delivery valve & 0.01 & $\mathrm{~m}$ \\
\hline Radius of the disk of the waste valve & 0.015 & $\mathrm{~m}$ \\
\hline Length of the delivery valve stroke & 0.006 & $\mathrm{~m}$ \\
\hline Length of the balloon membrane stroke & 0.085 & $\mathrm{~m}$ \\
\hline Inclination angle of the pump from the horizontal & 0 & $\circ$ \\
\hline Thickness of the supply pipe & 0.001 & $\mathrm{~m}$ \\
\hline Water density & 1000 & $\mathrm{~kg} \cdot \mathrm{m}^{-3}$ \\
\hline Roughness of the supply pipe & 0.000006 & $\mathrm{~m}$ \\
\hline Roughness of the delivery pipe & 0.000006 & $\mathrm{~m}$ \\
\hline The angle at the enlargement & 0 & $\circ$ \\
\hline Poisson's ratio of the supply pipe material & 0.46 & - \\
\hline The solid angle in the shrinkage & 0 & $\circ$ \\
\hline
\end{tabular}


The determination of the friction constant was done numerically. Therefore, obtained from Equation (1), the head losses of the delivery valve were plotted, as shown in Fig. 3, as a function of water velocity chosen randomly:

$$
H_{V}=K_{s} \frac{V^{2}}{2 g}
$$

Where:

$H_{V}=$ The singular head loss due to the delivery valve (m)

$K_{S}=$ The singular head loss coefficient of the delivery valve given by the manufacturer (dimensionless)

$V=$ The water velocity $\left(\mathrm{m} \cdot \mathrm{s}^{-1}\right)$

$g=$ The acceleration of gravity $\left(9.81 \mathrm{~m} \cdot \mathrm{s}^{-2}\right)$

Hence, the friction constant of the delivery valve is $7.77 \mathrm{~m} \cdot \mathrm{s}^{-1}$.

The other parameters of the model (Rajaonison and Rakotondramiarana, 2019) that characterize the experimental hydram pump are listed in Table 1.

The pumped water flow was measured for each change of the waste valve stroke, in steps of $0.0005 \mathrm{~m}$, ranging from 0.002 to $0.008 \mathrm{~m}$. This last value is the maximum that the experimental pump can reach. First, an amount of pumped water was collected during a certain time measured with an electronic chronometer. After that, the collected water was weighed with an electronic scale. Besides, each value of the pumped water flow was obtained by dividing the amount of water collected with the duration assigned to it. Each measurement of the amount of water was done in approximately the same duration. Furthermore, the reservoir was not entirely emptied but completely refilled after each measurement.

\section{Results and Discussion}

The results of the experiment by varying the waste valve stroke are given in Table 2 .
It can be seen that the experimental pumped water flow (Table 2 third column) does not correspond to the one given by the model (Table 2 fourth column) for the same value of the input parameter (Table 2 first column). However, the model output (Table 2 fifth column) can match the experimental output if the waste valve stroke is adjusted (Table 2 second column). Thus, a recalibration of the considered model seems necessary. That implies the experimental (Table 2 first column) and the adjusted (Table 2 second column) values of the waste valve stroke. The objective of such recalibration is to have the pumped water flow values given by the model best approach those obtained experimentally.

\section{Model Recalibration}

First, the singular values of the experimental data (Table 2 first column) are determined by a Gaussian Process framework for the analysis of Experimental Data (GPExp) (Rasmussen and Williams, 2017). More precisely, it is a free access Matlab coded tool that can analyze the experimental data by using Gaussian processes' regression (GP regression) to find data outliers. This could be done owing to the variation of the GP regression function variance with the data density and with the noise (e.g., the uncertainties in the measurements and/or the influence of external perturbations) added to the simulated data (Quoilin and Schrouff, 2016). Therefore, this tool helps determine the quality of outputs (waste valve stroke adjusted values, Table 2 second column) regarding the inputs (waste valve stroke experimental values, Table 2 first column) and can detect which input data points are likely to be outliers (Quoilin and Schrouff, 2016).

The experimental input and output data matrix are implemented in GPExp, in the form of a .csv file, a .mat file, or an Excel file. After running the tool, the results are illustrated in Fig. 4.

Table 2: Experimental and theoretical results of the experiment

\begin{tabular}{|c|c|c|c|c|}
\hline \multirow{2}{*}{\multicolumn{2}{|c|}{$\begin{array}{l}\text { Input parameter, } \\
\text { So: waste valve stroke (m) }\end{array}$}} & \multicolumn{3}{|c|}{ Output parameter, Pumped water flow $\left(\mathrm{L} . \mathrm{s}^{-1}\right)$} \\
\hline & & \multirow[b]{2}{*}{ Experimental value } & \multirow{2}{*}{$\begin{array}{l}\text { Model output without } \\
\text { adjusted waste valve stroke }\end{array}$} & \multirow{2}{*}{$\begin{array}{l}\text { Model output with adjusted } \\
\text { waste valve stroke }\end{array}$} \\
\hline Experimental value & Adjusted value & & & \\
\hline 0.002 & 0.002354 & 0.00402 & 0.00060 & 0.00402 \\
\hline 0.0025 & 0.002513 & 0.00559 & 0.00547 & 0.00559 \\
\hline 0.003 & 0.004016 & 0.01665 & 0.01001 & 0.01665 \\
\hline 0.0035 & 0.004565 & 0.02070 & 0.01244 & 0.02070 \\
\hline 0.004 & 0.004499 & 0.02024 & 0.01653 & 0.02024 \\
\hline 0.0045 & 0.004672 & 0.02163 & 0.02025 & 0.02145 \\
\hline 0.005 & 0.004459 & 0.01995 & 0.02698 & 0.01995 \\
\hline 0.0055 & 0.004741 & 0.02333 & 0.03509 & 0.02333 \\
\hline 0.006 & 0.004727 & 0.02313 & 0 & 0.02313 \\
\hline 0.0065 & 0.004762 & 0.02362 & 0 & 0.02362 \\
\hline 0.007 & 0.004682 & 0.02251 & 0 & 0.02251 \\
\hline 0.0075 & 0.005148 & 0.02914 & 0 & 0.02914 \\
\hline 0.008 & 0.004673 & 0.02212 & 0 & 0.02238 \\
\hline
\end{tabular}




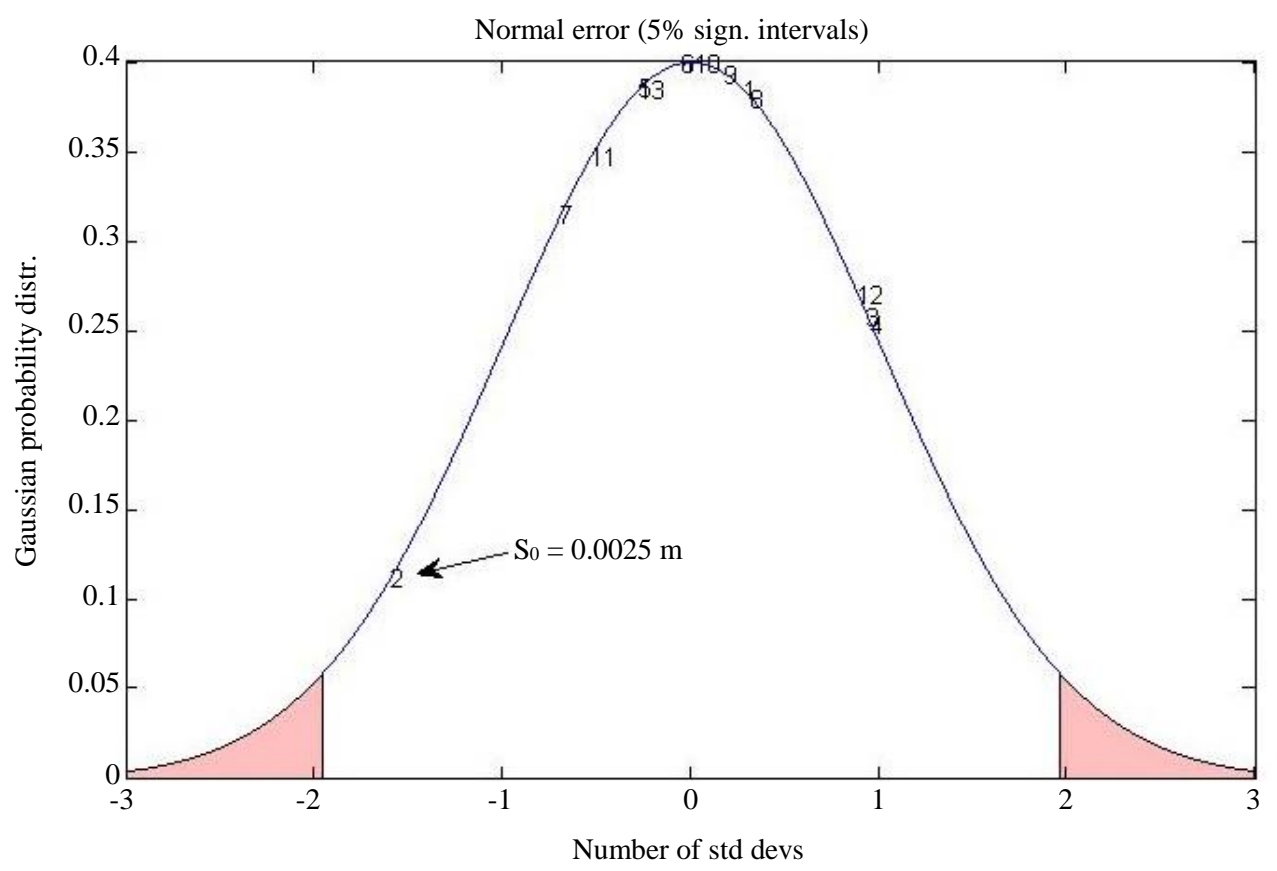

Fig. 4: Gaussian analysis of experimental data

Table 3: Experimental and model-computed values of pumped water flow after recalibration

\begin{tabular}{ll}
\hline Input parameter, & Output parameter, \\
So: waste valve stroke $(\mathrm{m})$ & $\begin{array}{l}\text { Pumped water flow }\left(\mathrm{L} . \mathrm{s}^{-1}\right) \\
\text { Model-recalibrated value }\end{array}$ \\
\hline Experimental value & 0.00637 \\
\hline 0.002 & 0.01566 \\
0.003 & 0.02051 \\
0.0035 & 0.02051 \\
0.004 & 0.02080 \\
0.0045 & 0.02109 \\
0.005 & 0.02138 \\
0.0055 & 0.02284 \\
0.006 & 0.02344 \\
0.0065 & 0.02405 \\
0.007 & 0.02466 \\
0.0075 & 0.02529 \\
0.008 &
\end{tabular}

As can be seen from Fig. 4, the data point with the highest probability to be an outlier is the second experimental one. In the first column of Table 2, it corresponds to the value of the waste valve stroke equal to $0.0025 \mathrm{~m}$. Then, this value was not considered to have a good adjustment.

Matlab lsqcurvefit function, which can solve nonlinear data-fitting problems in a least-squares sense (Matlab R2010a, 2010), was used to recalibrate the model. It was found that the waste valve stroke has two fitting curves that best fit the data. The first curve is in the form of an $a x^{b}$-equation for a waste valve stroke less or equal to $0.0035 \mathrm{~m}$ and the second one is an exponential function in the form of $a \exp ^{b}$ for a waste valve stroke between 0.0035 and $0.008 \mathrm{~m}$.
According to Equation (2), the recalibration of the model by the waste valve stroke is such that, for an input value, the model will adjust it as follows:

$S_{0}=\left\{\begin{array}{c}1.2964 S_{0} \text { if } S_{0} \leq 0.0035 m \\ 4.2172 * 10^{-3} \exp \left(18.2622 S_{0}\right) \text { if } 0.0035<S_{0} \leq 0.008\end{array}\right.$

where, $S_{0}$ is the waste valve stroke $(\mathrm{m})$.

Table 3 presents the results obtained after resetting the considered model.

After model recalibration, the values of the pumped water flow given by the model as shown in Table 3 second column fit well those obtained experimentally as presented in Table 2 third column.

For fully validating the model, the determination coefficient $\mathrm{R}^{2}$, which involves the experimental values (Table 2 third column), the computed ones (Table 3 second column) and the mean of the experimental ones, was computed. This coefficient contributes to highlighting the quality of a model based on the analysis of the variance of two variables, the experimental (the target) and computed (the predicted) values. $\mathrm{R}^{2}$ shows the correlation between the variables. Indeed, the variance of one variable is partly explained by the values taken by the second one. In other words, this coefficient shows that the variations of one variable depend on the variations of the second one (Bailly and Carrère, 2015). Therefore, the determination coefficient of the studied data is equal to 0.8857 . As this value is close to one, it can be asserted that the model is close to reality (Bailly and Carrère, 2015). 
Despite a slight adjustment of the input parameter waste valve stroke, the value of pumped water flow simulated by the model is generally near to the experimental one. Consequently, perspectives for future uses of the proposed mathematical model of the operation of the hydraulic ram pump with a springs system are now possible such as for the simulation of a full-scale water supply. Nevertheless, only one parameter out of thirty-one was adjusted.

\section{Conclusion}

This paper paves the way for advancements that could be done on a new type of hydram pump, the RASETA pump. This hydram pump is different from the conventional ones as springs are put to the waste valve, the delivery valve and the balloon usually filled with air. Following the development of a mathematical model of this new hydram pump type operation, the experimental validation of such a model allows future uses of it. Hence, the sizing of any system using this type of pump in any field is now possible.

However, it should be noted that the adjustment of the pump waste valve stroke was only for values less or equal to $0.008 \mathrm{~m}$. Thus, beyond this range, it will be necessary to make another adjustment of the parameter. Besides, only the most sensitive parameter of the model was adjusted. Consequently, for a better recalibration of the model, the other parameters should be adjusted which could be interesting future research on this hydraulic ram pump with a springs system.

\section{Author's Contributions}

Andriamahefasoa Rajaonison: Contribution includes experiment phases, literature redaction and provides the required funding for the paper.

Hery Tiana Rakotondramiarana: Supervised this work including providing guidance, direction and methodology and contributed to the manuscript proofread.

\section{Ethics}

This article is original and contains unpublished material. The corresponding author confirms that all of the other authors have read and approved the manuscript and no ethical issues involved.

\section{References}

Bailly, P. and C. Carrère, 2015. Statistiques Descriptives: L'économie et Les Chiffres. Presses Universitaires de Grenoble, Grenoble, ISBN-13: 9782706122156 , pp: 250.
Deo, A., C.C. Handa and A.P. Ninawe, 2016. Design methodology for hydraulic ram pump. Int. J. Innovative Res. Sci. Eng. Technol., 5: 4737-4745. DOI: 10.15680/IJIRSET.2016.0504018

Hussin, N.S.M., S.A. Gamil, N.A.M. Amin, M.J.A. Safar and M.S.A. Majid et al., 2017. Design and analysis of hydraulic ram water pumping system. J. Phys.: Conf. Series, 908: 1-8.

DOI: 10.1088/1742-6596/908/1/012052

Inthachot, M., S. Saehaeng, J.F.J. Max, J. Müller and W. Spreer, 2015. Hydraulic ram pumps for irrigation in Northern Thailand. Agric. Agric. Sci. Proc., 5: 107-114. DOI: 10.1016/j.aaspro.2015.08.015

Lansford, W.M. and W.G. Dugan, 1941. An analytical and experimental study of the hydraulic ram. Engineering experiment station. University of Illinois. Engineering Experiment Station. Bulletin. No. 326.

Maratos, D.F., 2003. Technical feasibility of wavepower for seawater desalination using the hydro-ram (Hydram). Desalination, 153: 287-293. DOI: $10.1016 / \mathrm{S} 0011-9164(02) 01148-7$

Matlab R2010a, 2010. High-performance numerical computation and visualization software. The Mathworks, Inc.: Natick, MA, USA.

Quoilin, S. and J. Schrouff, 2016. Assessing steady-state, multivariate experimental data using Gaussian processes: The GPExp open-source library. Energies, 9: 423-423. DOI: 10.3390/en9060423

Rajaonison, A. and H.T. Rakotondramiarana, 2019. Theoretical study of the behavior of a hydraulic ram pump with springs system. Am. J. Fluid Dynam., 9: 1-12. DOI: 10.5923/j.ajfd.20190901.01

Rakotondramiarana, H.T. and A. Andriamamonjy, 2013. MATLAB automation algorithm for performing global sensitivity analysis of complex system models with a derived FAST method. J. Comput. Model, 3: 17-56.

Rasetarivelo, 2004. Patent: Pompe à eau à système de ressorts sans autre source d'énergie que l'eau. OMAPI, Madagascar.

Rasmussen, C.E. and C.K.I. Williams, 2017. A Gaussian processes framework for the analysis of experimental data.

Sengupta, P.P. and J. Narula, 2013. RV form and function: A piston pump, vortex impeller, or hydraulic ram? JACC: Cardiovascular Imag., 6: 636-639. DOI: 10.1016/j.jcmg.2013.04.003

Sheikh, S., C.C. Handa and A.P. Ninawe, 2013. Design methodology for hydraulic ram pump (Hydram). Int. J. Mech. Eng. Rob. Res., 2: 170-175. DOI: $10.15680 /$ IJIRSET.2016.0504018 